\title{
Adsorption characteristics of ethanol root extract of Portulaca oleracea as eco-friendly inhibitor of corrosion of mild steel in $\mathrm{H}_{2} \mathrm{SO}_{4}$ medium
}

\author{
S. O. Adejo ${ }^{1 *}$, M. M. Ekwenchi ${ }^{2}$, P. O. Olatunde ${ }^{3}$, E. F. Agbajeola ${ }^{4}$ \\ ${ }^{1 \& 4}$ (Physical Chemistry Unit, Department of Chemistry, Benue State University, Makurdi-Nigeria) \\ ${ }^{2 \& 3}$ (Department of Pure and Industrial Chemistry, University of Jos, Jos-Nigeria)
}

\begin{abstract}
The adsorption of ethanolic root extract of Portulaca oleracea as corrosion inhibitor for the corrosion of mild steel in $\mathrm{H}_{2} \mathrm{SO}_{4}$ medium at the temperature range of $305 \mathrm{~K}$ to $315 \mathrm{~K}$ was studied using weight loss method and characterized using the common adsorption isotherms. The inhibition efficiency, IE\%, was found to increase with both increase in the inhibitor concentration and rise in temperature. The increase in IE\% with rise in temperature is suggestive of chemisorption. The adsorption best fitted the Langmuir, El-Awady, Temkin and Adejo-Ekwenchi isotherms. Evaluated values of free energy, $\Delta G_{\text {ads }}$, of the adsorption process were found to be all negative, indicative of spontaneity of the adsorption process and values obtained through the Temkin were above $-20 \mathrm{~kJ} / \mathrm{mol}$, supportive of the chemisorption. The fact that the slopes and intercepts of the ideal Langmuir isotherm (ILI) plots were not unity and zero, respectively, signifies a deviation from this isotherm but the deviation cannot be said to be much as $\Delta G_{\text {ads }}$ values obtained through modified Langmuir isotherm (MLI) are not quite different from those of ILI. The adherence of the adsorption to the Temkin isotherm is evidence evident of chemisorption, which was made evidently made clear from the Adejo-Ekwenchi $b$ parameter. The exact number of water molecules replaced by inhibitor molecules could not be ascertained by Bockris-Swinkels isotherm.
\end{abstract}

Keywords: Corrosion Inhibition, mild steel, Portulaca oleracea, Adsorption Isotherm, Chemisorption

\section{Introduction}

The reaction and subsequent deterioration of materials on exposition to the environment form the subject of corrosion. Corrosion breaks down the essential properties in a material. Corrosion control is of economic, environment and aesthetic importance [1-3]. Inhibitors have been used effectively to protect materials, especially metals, against the ravaging effects of corrosion for many years. To this effect synthetic inhibitors which have excellent inhibitive action are now of restricted use on the account of their harmful effects to human beings and environment, cost aside $[4,5]$. Therefore, attention has shifted to non-toxic and ecofriendly inhibitors. Many works have been carried out on plant extracts as they are found to meet the required properties of non-toxicity, bio-degradability, low cost, renewability, and ease of availability, coupled with simple procedural steps for their extraction [6].

As a contribution to the sustained interest in eco-friendly corrosion inhibitors the ethanol extract of leaves and roots of Portulaca oleracea have been investigated and found to inhibit the corrosion of mild steel in sulphuric acid medium [4,7]. Basic information on the interaction between the inhibitor and the metal surface can be provided by the adsorption isotherms using the surface coverage, $\theta$, at different concentrations and temperatures [8]. We hereby characterise the adsorption behaviour of the roots of the plant as inhibitor for the corrosion of mild steel in the sulphuric acid medium in furtherance of our work on this plant extract as inhibitor for the metal.

\section{Experimental}

Portulaca oleracea plant was collected, identified, shade-dried and the roots ground into powder and the extract obtained as reported earlier [4]. Stock solutions of concentrations of $0.1,0.2,0.3,0.4$ and $0.5 \mathrm{~g} / \mathrm{dm}^{3}$ of the extract were prepared in $2 \mathrm{M} \mathrm{H}_{2} \mathrm{SO}_{4}$ using double distilled. All reagents used were of analytical grade.

Coupons of dimension of $2 \mathrm{~cm} \times 2 \mathrm{~cm} \times 0.13 \mathrm{~cm}$ were prepared from the mild steel sample of composition (\%W): $\mathrm{Mn}(0.56), \mathrm{P}(0.04), \mathrm{C}(0.27), \mathrm{Si}(0.25), \mathrm{S}(0.04)$ and rest Fe. Each coupon was first weighed accurately, after degreasing in acetone, with the surface prepared with different grade of emery papers. Through a very thin hole borne at the edge of each coupon was suspended in $100 \mathrm{~mL}$ of the test solution using thread for a period of 8 hours in a thermostated water bath without and with various concentrations of the extract at $303 \mathrm{~K}$ to $315 \mathrm{~K}$. After the time interval the coupons were retrieved and the reaction terminated accordingly, and then stored in a desiccator and reweighed afterwards $[7,9]$. The inhibition efficiency, IE\%, and surface coverage, $\theta$, were calculated using "equations1 and 2", respectively $[4,10]$. 


$$
\begin{array}{ll}
\mathrm{IE} \% & =1-\frac{\mathrm{W}_{\text {inh }}}{\mathrm{W}_{\text {uninh }}} \times 100 \\
\theta & =\left(1-\frac{\mathrm{W}_{\text {inh }}}{\mathrm{W}_{\text {uninh }}}\right)
\end{array}
$$

where $\mathrm{W}_{\text {uninh }}$ and $\mathrm{W}_{\mathrm{inh}}$ are weight losses in absence and presence of inhibitor, respectively.

\section{Results and Discussion}

Table 1 shows inhibition efficiency at different concentrations and temperatures. The inhibition efficiency of the extract was found to increase with increase in both the concentration and temperature. The increase in inhibition efficiency with increase in temperature could be suggestive of chemisorption as the mechanism for the adsorption of the extract onto the surface of the metal [1]. When compared with the inhibition efficiency of the leaves extract, the root not only has lower efficiency but completely opposite [4, 7]. This may be an indication of differences in bioactive composition of the different parts of this plant. In fact, it has been reported that the entire plant is used as antibacterial, anti-inflammatory and anthelmintic, except the roots [11].

Table 1. Variation of inhibition efficiency with concentration of the Extract at different temperatures

\begin{tabular}{lccll}
\hline $\begin{array}{l}\text { Conc. } \\
\left(\mathrm{g} / \mathrm{dm}^{3}\right)\end{array}$ & $303 \mathrm{~K}$ & $307 \mathrm{~K}$ & $311 \mathrm{~K} 315 \mathrm{~K}$ & \\
\hline 0.1 & 32.00 & 34.59 & 35.12 & 37.44 \\
0.2 & 34.40 & 36.35 & 38.47 & 39.34 \\
0.3 & 36.13 & 38.49 & 42.82 & 44.58 \\
0.4 & 37.28 & 39.78 & 43.38 & 46.72 \\
0.5 & 39.46 & 40.33 & 48.51 & 49.07 \\
\hline
\end{tabular}

The variation of the inhibition efficiency with the logarithm of inhibitor concentration at $315 \mathrm{~K}$ is shown in Fig. 1. The S-shaped of the curve shows a formation of protective barrier of film of the inhibitor molecules on the metal surface $[12,13]$. This is a further evidence to support the inhibitive action of the extract against the corrosion of the metal.

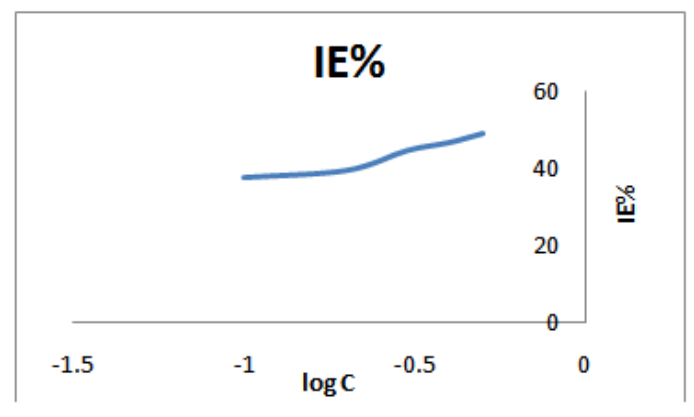

Fig.1 Relationship between inhibition efficiency and logarithm of concentration of inhibitor

One of the acceptable postulates being used as regards inhibitor action is formation of surface layers and films on the metal surface, thereby reducing the accessibility of the corrosion materials to the surface. The relationship between the amount of substance attached (adsorbed) to the surface to its concentration in gas or solution phase at a particular temperature is known as adsorption isotherm. Adsorption isotherm is usually described by an isotherm equation whose parameters express the surface properties and affinity of the adsorbate and from which the mechanism of adsorption process can be deduced [3]. And the most frequently used adsorption isotherms to characterise inhibitor behaviour in corrosion process are the Langmuir, Frumkin, Parsons, Temkin, Hill de Boer, Flory-Huggins, Bockris-Swinkels and the El-Awady thermodynamic-kinetic model $[4,14]$.

The calculated surface coverage values were graphically tested to find their suitability to the adsorption isotherms, using their regression coefficient, $\mathrm{R}^{2}$, values. On this account, the data fitted the Langmuir, Freundlich, El-Awady and Temkin, as shown in Table 2. The evaluated values of adsorption equilibrium constant, $\mathrm{K}_{\mathrm{ads}}$, are all higher than unity, implying favourable adsorption of the extract onto the metal surface.

The fact that the slopes and intercepts of Langmuir plots are not are not unity and zero, respectively, at all the temperatures shows that there is a deviation from this isotherm $[6,15]$. The non-total conformity might 
be as the result of molecular interaction among the adsorbed inhibitor molecules on the metal surface [16, 17]. Actually, it has been argued that given the complexity of the plant extracts composition, the different components may be adsorbed at the active sites on the metal surface, and such adsorbed species may interact by mutual repulsion or attraction, thereby making the adsorption not to strictly follow the ILI. More so, the study was carried in solution system where the adsorption process hardly totally follows the ILI. Consequently, the adsorption data were fitted to the Modified Langmuir isotherm (MLI) "equation 3" proposed by Villamil and Co-workers [18].

$$
\frac{\mathrm{C}}{\theta} \quad=\frac{\mathrm{n}}{\mathrm{K}_{\mathrm{ads}}}+\mathrm{nC}
$$

The parameter $\mathrm{n}$ is the slope of the plot of $\mathrm{C} / \theta$ against $\mathrm{C}$. The values of $\Delta \mathrm{G}_{\text {ads }}$ obtained through the MLI -18.32, $19.21,-17.45$ and $-17.93 \mathrm{~kJ} / \mathrm{mol}$ at $303,307,311$ and $315 \mathrm{~K}$, respectively. These values are not significantly different from those obtained through ILI, but are different from those obtained through" equations 4 and 5 " [2, $19,20]$, showing no serious deviation occurred from the ILI. In fact, the intercepts are not too far from the zero.

where

$$
\Delta \mathrm{G}_{\mathrm{ads}} \quad=-2.303 \mathrm{RT} \log (55.5 \mathrm{~K})
$$

$$
\mathrm{K}=\frac{\theta}{(1-\theta) \mathrm{C}}
$$

$\mathrm{C}$ is the concentration of inhibitor and 55.5 is water concentration solution expressed in moles (i.e. $\sim 1000$ $\left.\mathrm{g} / \mathrm{dm}^{3}\right)$. However, these values are all below $-20 \mathrm{~kJ} / \mathrm{mol}$. The interaction can, therefore, be said to more or less weak electrostatic interactions as the energy values are of the range of the van der Waal, London forces, dipole-dipole attractions, etc. which are actually of weak forces [14, 21, 22]. As observed above the variation of $\mathrm{IE} \%$ with temperature is a clear trend of chemisorption, but the obtained $\Delta \mathrm{G}_{\text {ads }}$ values are below $-20 \mathrm{~kJ} / \mathrm{mol}$ the threshold value for physical adsorption. This is an indication of mix features of chemical and physical adsorption mechanisms, which may be due to the fact that many different chemical compounds are usually present in plant extracts, which some can be adsorbed chemically and other physically [1].

The values of dimensionless constant called Langmuir equilibrium parameter, $\mathrm{R}_{\mathrm{L}}$, for the adsorption of this extract unto the mild steel surface are given in Table 4 . The values are all less than one but greater than zero, indicative of favourable adsorption $[14,23] . \mathrm{R}_{\mathrm{L}}$ has been observed to decrease with increase in both concentration and temperature, signifying more favourable adsorption with increase in concentration and rise in temperature.

The values of parameter $n$ of the Freundlich isotherm are far from the typical value of 0.6 [14], meaning this adsorption cannot be modeled by the Freundlich isotherm, in spite of the seemly good $\mathrm{R}^{2}$ values obtained from the plots (Table 2). This is a pointer to the fact that the adsorption is not actually too far from ideal adsorption process. The fact that this adsorption does not reasonably follow Freundlich may mean that it is monolayer molecular adsorption, a feature of chemisorption.

The El-Awady isotherm parameter $\mathrm{y}$ is less than unity at all temperatures, signifying a monolayer adsorption [6,12], and evidently supportive of chemical adsorption process. 1/y values are 5.1387, 6.2539, 2.9223 and 2.8482 at $303,307,311$ and $315 \mathrm{~K}$, respectively. These values are approximately equal to the number of water molecules $\mathrm{n}$ replaced by one inhibitor molecule [6]. The value of $\mathrm{n}$ varies with temperature, meaning the number of water molecules that were replaced varied also with temperature. Values of $\Delta \mathrm{G}_{\mathrm{ads}}$ obtained through this isotherm are more close to those obtained through equilibrium constant than from other isotherms. This shows that the adsorption can be better fitted into this isotherm. 
Table 2. Various Adsorption isotherms parameters for adsorption of the extract of roots of Portulaca oleracea onto the mild steel surface

\begin{tabular}{|c|c|c|c|c|c|c|c|c|}
\hline $\begin{array}{l}\text { Isotherm } \\
(\mathrm{K})\end{array}$ & Temp & $\mathrm{R}^{2}$ & Slope & Intercept & $\mathrm{K}_{\mathrm{ads}}$ & & & $\begin{array}{c}-\Delta \mathrm{G}_{\mathrm{ads}} \\
(\mathrm{kJ} / \mathrm{mol})\end{array}$ \\
\hline \multicolumn{9}{|l|}{ Langmuir } \\
\hline & 303 & 0.9968 & 2.4008 & 0.0926 & 10.7991 & & & 16.11 \\
\hline & 307 & 0.9993 & 2.3573 & 0.0655 & 15.2672 & & & 17.21 \\
\hline & 311 & 0.9878 & 1.8942 & 0.1234 & 8.1037 & & & 15.78 \\
\hline & 315 & 0.9944 & 1.8515 & 0.1093 & 9.1413 & & & 16.33 \\
\hline \multirow[t]{5}{*}{ Freundlich } & & & & & & $\mathrm{n}$ & & \\
\hline & 303 & 0.9397 & 0.1281 & -0.3676 & 0.4289 & 0.1281 & & 7.99 \\
\hline & 307 & 0.9844 & 0.1001 & -0.3634 & 0.4331 & 0.1001 & & 8.12 \\
\hline & 311 & 0.9393 & 0.1903 & -0.2725 & 0.5339 & 0.1903 & & 8.76 \\
\hline & 315 & 0.9416 & 0.1751 & -0.2622 & 0.5468 & 0.1751 & & 8.94 \\
\hline \multirow[t]{5}{*}{ El-Awady } & & & & & & $\mathrm{K}^{\prime}$ & $\mathrm{y}$ & \\
\hline & 303 & 0.9764 & 0.1944 & -0.1391 & 1.9246 & 0.7259 & 0.1946 & 11.77 \\
\hline & 307 & 0.9829 & 0.1599 & -0.1212 & 1.7461 & 0.7565 & 0.1599 & 11.68 \\
\hline & 311 & 0.8977 & 0.3422 & +0.0570 & 1.4673 & 1.1402 & 0.3422 & 11.38 \\
\hline & 315 & 0.9065 & 0.3511 & +0.1025 & 1.9586 & 1.2662 & 0.3511 & 12.28 \\
\hline \multirow[t]{5}{*}{ Temkin } & & & & & & $\alpha$ & & \\
\hline & 303 & 0.9661 & 9.5791 & -4.0187 & $1.0440 \times 10^{4}$ & -11.0303 & & 33.41 \\
\hline & 307 & 0.9816 & 11.3980 & -4.9058 & $8.0501 \times 10^{4}$ & -13.1248 & & 39.09 \\
\hline & 311 & 0.9243 & 5.1996 & -2.7503 & 562.7299 & -5.9873 & & 26.76 \\
\hline & 315 & 0.9334 & 5.4269 & -2.9411 & 873.1724 & $\begin{array}{c}-6.2491 \\
\text { b }\end{array}$ & & 28.26 \\
\hline Adejo- & 303 & 0.9958 & 0.0578 & 0.2246 & 1.6773 & 0.0578 & & 11.42 \\
\hline \multirow[t]{3}{*}{ Ekwenchi } & 307 & 0.9697 & 0.0598 & 0.2422 & 1.7466 & 0.0598 & & 11.68 \\
\hline & 311 & 0.9580 & 0.1048 & 0.2908 & 1.9534 & 0.1048 & & 12.12 \\
\hline & 315 & 0.9264 & 0.1187 & 0.3154 & 2.0673 & 0.1187 & & 12.42 \\
\hline \multirow{2}{*}{\multicolumn{3}{|c|}{ Bockris-Swinkels }} & \multicolumn{4}{|c|}{ Average of $-\Delta \mathrm{G}_{\mathrm{ads}}(\mathrm{kJ} / \mathrm{mol})$} & & \\
\hline & & & $\mathrm{n}=1$ & $\mathrm{n}=2$ & & $=3$ & $\mathrm{n}=4$ & \\
\hline & 303 & & 12.08 & 10.92 & 9. & 03 & 7.30 & \\
\hline & 307 & & 12.42 & 11.34 & 9. & 35 & 7.54 & \\
\hline & 311 & & 12.99 & 11.99 & & 86 & 7.89 & \\
\hline & 315 & & 13.35 & 12.39 & 10. & 17 & 8.11 & \\
\hline
\end{tabular}

Table 3. Values $\Delta G_{\text {ads }}$ obtained through equilibrium constant

\begin{tabular}{lcccc}
\hline $\begin{array}{c}\text { Conc. } \\
\left(\mathrm{g} / \mathrm{dm}^{3}\right)\end{array}$ & \multicolumn{3}{c}{$\begin{array}{c}-\Delta \mathrm{G}_{\text {ads }} \\
(\mathrm{kJ} / \mathrm{mol})\end{array}$} \\
\hline 0.1 & $303 \mathrm{~K}$ & $307 \mathrm{~K}$ & $311 \mathrm{~K}$ & $315 \mathrm{~K}$ \\
0.2 & 14.02 & 14.50 & 14.75 & 15.21 \\
0.3 & 12.73 & 12.94 & 13.33 & 13.60 \\
0.4 & 11.72 & 12.13 & 12.75 & 13.10 \\
0.5 & 11.12 & 11.53 & 12.07 & 12.58 \\
Average & 10.79 & 11.02 & 12.03 & 12.24 \\
\hline
\end{tabular}

Temkin isotherm, in fact, is a characteristic of chemisorption of uncharged molecules on a heterogeneous surface. The adherence of the data to Temkin isotherm is, therefore, a clear indication of the participation of molecular species in the adsorption [24] and the negative values of parameter $\alpha$ show repulsive interaction. The values of $\Delta \mathrm{G}_{\mathrm{ads}}$ are within the values for chemisorption, as they are all between $-20 \mathrm{~kJ} / \mathrm{mol}$ and $-40 \mathrm{~kJ} / \mathrm{mol}$.

Table 4. Values of $\mathbf{R}_{\mathrm{L}}$ for different concentrations at various temperatures for roots extract of Portulaca

\begin{tabular}{lcccc}
\multicolumn{5}{c}{ oleracea } \\
\hline $\begin{array}{l}\text { Conc. } \\
\left(\mathrm{g} / \mathrm{dm}^{3}\right)\end{array}$ & \multicolumn{4}{c}{$\mathrm{R}_{\mathrm{L}}$} \\
& $303 \mathrm{~K}$ & $307 \mathrm{~K}$ & $311 \mathrm{~K}$ & $315 \mathrm{~K}$ \\
\hline 0.1 & 0.9721 & 0.9506 & 0.9345 & 0.9066 \\
0.2 & 0.9456 & 0.9058 & 0.8771 & 0.8291 \\
0.3 & 0.9206 & 0.8651 & 0.8263 & 0.7638 \\
0.4 & 0.8969 & 0.8278 & 0.7811 & 0.7981 \\
0.5 & 0.8744 & 0.7937 & 0.7406 & 0.6599 \\
\hline
\end{tabular}


A newly proposed Adejo-Ekwenchi is given by“ equation 6”.

$$
\log \frac{1}{(1-\theta)}=\log \mathrm{K}_{\mathrm{AE}}+\operatorname{blog} \mathrm{C}
$$

The parameter $\mathrm{b}$ of the isotherm can be used distinguish between physical and chemical adsorption. From Table 3 it can be clearly seen that the adsorption mechanism is chemisorption as b fairly increases with rise in temperature. This has eliminated the idea of mix adsorption stated above. In fact, the Adejo-Ekwenchi isotherm parameter $\mathrm{b}$ can help resolve the ambiguity usually associated with the use of R2 and $\Delta$ Gads values in characterisation of adsorption process as reported in literatures [25, 26]. Therefore, this adsorption can be assertively said to be chemisorption.

The adsorption of an organic adsorbate onto metal-solution interface has been denoted as a substitutional adsorption process between the organic molecules in the aqueous solution and water molecules on the metal surface according to "equation 7",

$$
\operatorname{Org}_{(\text {sol })}+\mathrm{nH}_{2} \mathrm{O}_{(\text {ads })} \rightarrow \operatorname{Org}_{(\text {ads })}+\mathrm{nH}_{2} \mathrm{O}_{(\text {sol })}
$$

where $\operatorname{Org}_{(\text {soln })}$ and $\operatorname{Org}_{(\text {ads })}$ are the organic molecules in aqueous solution and adsorbed on the metal surface, respectively, $\mathrm{H}_{2} \mathrm{O}_{(\mathrm{ads})}$ is water molecules on the metal surface and $\mathrm{n}$ is the size ratio representing the number of water molecules replaced by one molecule of organic adsorbate [27]. Average values of $\Delta \mathrm{G}_{\mathrm{ads}}$ calculated using the Bockris-Swinkels isotherm "equation 8"are shown in Table (2).

$$
\Delta \mathrm{G}_{\mathrm{ads}}=-2.303 R T \log \left\{55.5 \theta / \mathrm{C}(1-\theta)^{\mathrm{n}} \times[\theta+(1-\theta) \mathrm{n}]^{\mathrm{n}-1} / \mathrm{n}^{\mathrm{n}}\right\}
$$

Where $\mathrm{n}$ is the number of water molecules being replaced by inhibitor molecules? The value are all negative and below $-20 \mathrm{~kJ} / \mathrm{mol}$ and increases with increase in temperature and decreases as the number of $\mathrm{n}$ increases. Values of $\Delta \mathrm{G}_{\mathrm{ads}}$ for $\mathrm{n}=1$ to 4 point to the fact that $\mathrm{n}$ value is likely to be 4 for Freundlich and 2 for El-Awady. However, it cannot be inferred from the other isotherms. As pointed out elsewhere [4], the extract is a mixture of many compounds which may not be of same size, and therefore, the inherent problem in trying to use Bockris-Swinkels isotherm to characterise adsorption process of extracts is very obvious.

\section{Conclusion}

The following conclusions can be draw from the results:

- The inhibition efficiency of ethanol extract of roots of Portulaca oleracea for the inhibition of corrosion of mild steel in $\mathrm{H}_{2} \mathrm{SO}_{4}$ medium increases with both increase in the extract concentration and temperature.

- The adsorption of the extract unto the surface of the metal best fitted the Langmuir, El-Awady, Temkin and Adejo-Ekwenchi isotherms.

- The parameter $b$ of the Adejo-Ekwenchi isotherm increases with temperature, therefore, the adsorption follows chemical adsorption mechanism.

\section{Acknowledgements}

The Authors wish to acknowledge the immense assistance received from Mr. Waya of Department of Biological Sciences and staff of Chemistry Department of the Benue State University, Makurdi-Nigeria during the bench work.

\section{References}

[1]. E. I. Ating, S. A. Umoren, I.I .Udousoro, E. E. Ebenso, and A P Udoh, Green Chemical Letter and Review,3. 2010, 61-68.

[2]. L. A. Nnanna, B. N. Onwuagba, I. M. Mejeha, and K. B. Okeoma, Inhibition effects of some plant extracts on the acid corrosion of aluminium alloy, African Journal Pure and Applied Chemistry, 4, 2010, 011-016

[3]. J. A. Selvi, S. Rajendran, and V G Sri, Corrosion Inhibition of beet root extract, Portugaliae Electrochimica Acta,27,2009, 001-011.

[4]. S. O. Adejo, M. M. Ekwenchi, F. Momoh, and E. O. Odiniya, Adsorption characterization of ethanol extract of leaves of Portulaca oleracea as green corrosion inhibitor for corrosion of mild steel in sulphuric acid medium, International Journal of Modern Chemistry, 3, 2012, $125-134$.

[5]. A. S. Fouda, G. Y. Elewady , and M. N. El-Haddad, Corrosion inhibition of carbon steel in acidic solution using some azodyes, Canadian Journal on Science and Industrial Research, 21, 2011, 01-17.

[6]. R. Saratha, and R. Meenakshi, Saratha, R. and Meenakshi, R. (2010). Corrosion inhibitor - A plant extract, Der Pharma Chemica, 2, 2010, $287-294$.

[7]. S. O. Adejo, M. M. Ekwenchi, E. O. Odiniya, J. P. Acholo, and S. P. Banke, Ethanol extract of leaves of Portulaca oleracea as green inhibitor for corrosion of mild steel in $\mathrm{H}_{2} \mathrm{SO}_{4}$ medium, Proc. $3^{\text {rd }}$ Annual International Conference on Research and Development, Accra-Ghana, 2010, 113 - 118. 
[8]. P. C. Okafor, E. E. Ebenso, and U. J. Ekpe, Azadirachta Indica extracts as corrosion inhibitor for mild steel in acid medium, International Journal of Electrochemical Sciences, 5, 2010, 978-993.

[9]. K. Orubite-Okorosaye, N.C. Oforka, Corrosion inhibition of zinc on HCl using Nypa fruiticans Wurmb extract and 1,5-Diphyeny carbazone, Journal of Applied Science and Environmental Management,8, 2004, 57- 61.

[10]. A. Singh, V. K. Singh, and M. A .Quraishi .Aqueous extract of Kalmegh (Andrographis paniculata) leaves as green inhibitor for mild steel in hydrochloric acid solution, International Journal of Corrosion,2010, $01-10$.

[11]. S. D. Sanja, N. R. Sheth, N. K. Patel, D. Patel, and B. Patel, Characterisation and evaluation of antioxidant activity of Portulaca oleracea, International Journal of Pharmacy and Pharmaceutical Sciences, 1, 2009,74- 75.

[12]. I. B. Obot, N. O. Obi-Egbedi, and S. A. Adsorption characterisation and corrosion inhibitive properties of clotrimazole for aluminium corrosion in hydrochloric acid, International Journal of Electrochemical Science,5, 2010, 994-1007.

[13]. O. K. Abiola, Adsorption of methionine on mild steel. Journal of Chilean Chemical Society,50, 2005, 685-690.

[14]. A. A. Khadom, A. S. Yaro, and A. A. H. Kadhum, Adsorption mechanism of benotriazole for corrosion inhibition of copppernickel alloy in hydrochloric acid, Journal of the Chilean Chemical Society, 55, 2010, 150-152.

[15]. I. B. Obot, N. O. Obi-Egbedi, S. A. Umoren, Adsorption characterisation and corrosion inhibitive properties of clotrimazole for aluminium corrosion in hydrochloric acid, International Journal of Electrochemical Science, 4, 2009, 863-877.

[16]. I. M Mejeha, A. A. Uroh, K. B. Okeoma, and G. A. Alozie, The inhibitive effect of Solanum melonena L. leaf extract on the corrosion of aluminium in tetraoxosulphate (VI) acid, African Journal of Pure and Applied Chemistry,4, $2010,158-165$.

[17]. R. N. Nair, S. Sharma, I. K. Sharma, P. S. Verma , and A. Sharma, Inhibitory efficacy of Piper nigrum Linn, extract on corrosion of AA1100 in HCL. RASAYAN Journal of Chemistry, 3(4), 783-795.

[18]. I. B. Obot, S. A. Umoren, N. O. Obi-Egbedi, Corrosion inhibition and adsorption behaviour for aluminium by extract of Aningeria robust in $\mathrm{HCl}$ solution: Synergistic effect of iodide ions, Journal of Material and Environmental Science,2, 2011, 60-71.

[19]. D. M. Bastidas, P. P. Gomez, and E. Cano, The isotherm slope: A criterion for studying the adsorption mechanism of benzotriazole on copper in sulphuric acid, Revista Metallurgy, 41, 2005, 98-106.

[20]. H. A. Al-Lohedan, E. Khamis, and Z. A. Issa, Studies on the influence of temperature on the adsorption of some cationic surfactants onto steel, Adsorption Science and Technology,13,1996 137-153

[21]. R. G. Mortimer, Physical chemistry $3^{\text {rd }}$ ed (Elsevier Academic Press, UK, 2008).

[22]. P. W. Atkins, Physical Chemistry $2^{\text {nd }}$ ed (W.H .Freeman and Company San Francisco, U.S.A, 1982).

[23]. S. O. Adejo, R. A. Wuana, E. A. Ieave, and M. O. Angba, Evaluation of physicochemical and adsorptive properties of adsorbent prepared from Sorghum bicolor (Guinea-corn) husks. The Nigerian Journal of Pure and Applied Sciences,2, 2008, $001-009$.

[24]. S. O. Adejo, and M. M. Ekwenchi, Proposing a new empirical adsorption isotherm known as Adejo-Ekwenchi, IOSR Journal of Applied Chemistry, 6, 2014, 66-71.

[25]. Y. S. Ho, J. F. Porter and G. McKay, Equilibrium isotherm studies for the sorption of divalent metal ions onto peat: copper, nickel and lead single component systems, Water, Air and Soil Pollution, 141, 2002, 1-33.

[26]. A. Popova, M. Christov, A. Vasilev and A. Zwetanova, Mono- and Dicationic Benzothiazolic Quaternary Ammonium Bromides as Mild Steel Corrosion Inhibitors. Part I: Gravimetric and Voltammetric Results. Corrosion Science, 53, 2011, 679-68.

[27]. S. A. Umoren and I. B. Obot, and I. O. Igwe, Synergistic inhibition between polyvinylpyrollidone and iodide ions on corrosion of aluminium in $\mathrm{HCl}$, The Open Corrosion Journal, 2, 2009, 1 - 7 . 